\title{
Comparison of automated and manual FISH for evaluation of HER2 gene status on breast carcinoma core biopsies
}

\author{
Christian Öhlschlegel, Doris Kradolfer, Margreth Hell and Wolfram Jochum*
}

\begin{abstract}
Background: Positive HER2 status identifies breast carcinomas that might respond to trastuzumab treatment. Manual HER2 fluorescent in situ hybridisation (FISH) is the most readily used method to detect HER2 gene amplification which defines positive HER2 status in addition to HER2 protein overexpression. Automation of HER2 FISH may improve HER2 gene testing. The aim of our study was to evaluate an automated HER2 FISH assay for assessing the HER2 genomic status.

Methods: Core biopsies of 100 invasive breast carcinomas were analysed in parallel using the PathVysion ${ }^{\text {TM }}$ HER-2 DNA Probe Kit and the Leica HER2 FISH System for BOND ${ }^{\mathrm{TM}}$. To assess inter-method agreement, concordance analysis was performed for various numerical and categorical HER2/CEP17 FISH parameters.

Results: Carcinomas with all HER2 immunohistochemical scores were included (0+: 20; $1+: 20 ; 2+: 30 ; 3+$ : 30). Using either HER2/CEP17 ratio >2.2 or $\geq 2.0$ as criterion for HER2 amplification, high levels of concordance were observed between automated and manual FISH (concordance rate 96\%, K coefficient 0.92). High levels of inter-method agreement were also found for HER2 copy number, CEP17 copy number, HER2/CEP17 ratio, the percentage of carcinoma cells with HER2/CEP17 ratio >2.2, and the presence of HER2 genetic heterogeneity, HER2 clusters and CEP17 polyploidy.

Conclusions: HER2 testing using automated FISH is feasible on breast carcinoma core biopsies. Automated HER2 FISH using the Leica HER2 FISH System for BOND is a practical and efficient alternative to manual HER2 FISH in evaluating the HER2 status of primary invasive breast carcinomas.
\end{abstract}

Keywords: Breast cancer, HER2, Automated FISH

\section{Background}

Trastuzumab treatment in patients with invasive breast cancer is based on the HER2 status of carcinoma cells [1]. According to ASCO/CAP recommendations, positive HER2 status is defined as uniform, intense membranous HER 2 protein expression in $>30 \%$ of tumour cells or HER2 gene amplification in carcinoma cells [2]. Determination of HER2 status can be performed either by HER2 protein expression analysis using immunohistochemistry (IHC) or HER2 gene copy number analysis. Manual fluorescent in situ hybridization (FISH) is the current most readily used method to determine the

\footnotetext{
* Correspondence: wolfram.jochum@kssg.ch

Institute of Pathology, Kantonsspital St. Gallen, Rorschacher Strasse 95, $\mathrm{CH}-9007$, St. Gallen, Switzerland
}

HER2 genomic status. Alternative in-situ methods such as silver-enhanced in-situ hybridization (SISH) and chromogenic in-situ hybridization (CISH) have been developed to detect HER2 gene amplification [3]. For these bright field HER2 in-situ hybridization methods, manual and automated assays have demonstrated high overall agreement with manual HER2 FISH [4-8].

The aim of this study was to evaluate a new fully automated HER2 FISH assay, the Leica HER2 FISH System for $\mathrm{BOND}^{\mathrm{m}}$, in comparison with manual HER2 FISH using the PathVysion ${ }^{\text {mox }}$ HER-2 DNA Probe Kit. We provide data that automated HER2 FISH enables accurate assessment of HER2 gene status on breast carcinoma core biopsies. 


\section{Methods}

\section{Patient tumour samples}

A series of 100 invasive breast carcinoma core needle biopsy specimens were retrieved from the surgical pathology files of the Institute of Pathology, Kantonsspital St. Gallen. Patients were diagnosed between 2008 to 2010. Carcinomas were classified according to the WHO Classification of Tumours of the Breast (2012). The 100 cases comprised 91 invasive ductal carcinomas (91\%) and 9 invasive lobular carcinomas (9\%).

The study was approved by the local ethics committee (Ethikkommission St. Gallen).

\section{Histology}

Haematoxylin-eosin (HE) staining was performed using standard histological techniques. HE-stained sections were used to select areas with invasive carcinoma for subsequent HER2 immunostaining and HER2 FISH. Carcinoma in situ was excluded from the analysis. To correlate HER2 immunostaining and HER2 FISH results at the cellular level, areas of interest were marked to compare manual and automated HER2 FISH results from corresponding areas of serial sections of carcinoma core biopsies.

\section{HER2 immunohistochemistry}

HER2 protein status of carcinoma cells was assessed using the Leica Bond ${ }^{\mathrm{TM}}$ Oracle $^{\mathrm{TM}}$ HER2 IHC System (Leica Biosystems Newcastle Ltd, UK) on a Leica BOND-MAX ${ }^{\mathrm{mm}}$ instrument. HER2 protein expression was scored as $0+$ (no staining), $1+$ (weak and incomplete membrane staining), $2+$ (strong, complete membrane staining in $\leq 30 \%$ of tumour cells or weak/moderate heterogeneous complete membrane staining in $\geq 10 \%$ of tumour cells), or $3+$ (strong, complete, homogeneous membrane staining in $>30 \%$ of tumour cells) [2]. Based on the HER2 immunohistochemical score, 100 carcinomas with scores $0+(\mathrm{n}=20), 1+(\mathrm{n}=20), 2+(\mathrm{n}=30)$, and $3+(\mathrm{n}=30)$ were selected for subsequent HER2 FISH analysis.

\section{HER2 FISH}

Manual HER2 FISH was performed using the PathVysion ${ }^{\mathrm{TM}}$ HER-2 DNA Probe Kit (Abbott Molecular Inc., Downers Grove, IL). For automated HER2 FISH, the fully automated Leica HER2 FISH System for BOND ${ }^{\text {тм }}$ (Leica Biosystems Newcastle Ltd, UK) was used on a Leica BOND MAX ${ }^{\mathrm{T}}$ instrument. This test contains the same probes used in the manual PathVysion ${ }^{\mathrm{Tm}}$ kit presented as ready to use dual HER2 and chromosome 17 FISH probes, allowing simultaneous determination of both HER2 and chromosome 17 copy number. The technique was performed as per the manufacturer's instructions, using the default 'FISH protocol A' on the Leica BOND System. At least 60 invasive carcinoma cells in at least three randomly selected areas of invasive carcinoma were scored for nuclear HER2 and chromosome 17 centromeric probe (CEP17) signals using a Leica DM6000B fluorescence microscope system (Leica Microsystems, Heerbrugg, Switzerland) equipped with a triple bandpass filter set (DAPI/Spectrum Green/Spectrum Orange). The FISH result for each carcinoma cell was recorded in a table, which was used to calculate the HER2/CEP17 ratio and to determine the frequency of tumour cells with a HER2/CEP17 ratio $>2.2$. If the average $H E R 2 / C E P 17$ ratio of 60 carcinoma cells was 1.8 to 2.2 (equivocal), another 40 invasive carcinoma cells were scored, and the final ratio of the tumour was calculated from the 100 cells.

Using the ASCO/CAP recommendations [2], a tumour was classified as HER2 nonamplified (HER2/CEP17 ratio $<1.8)$, equivocal $(H E R 2 / C E P 17$ ratio $1.8-2.2)$, or amplified (HER2/CEP17 ratio > 2.2). Two alternative definitions of positive HER2 amplification status were also tested: mean number of HER2 signals $>6.0$ in carcinoma cells and HER2/CEP17 ratio >2.0 [2]. HER2/ CEP17 ratio $>2.0$ was used as it represents the evaluation criterion recommended by the manufacturer of the PathVysion ${ }^{\mathrm{Tx}}$ HER-2 DNA Test. HER2 genetic heterogeneity was defined as more than $5 \%$ but less than $50 \%$ of invasive tumour cells with a ratio higher than 2.2 [9]. The percentage of carcinoma cells with HER2 gene cluster (defined as more than 16 HER2 signals per nucleus or the presence of not individually separable HER2 signals) was also determined. HER2 cluster positive carcinomas were defined by the presence of HER2 gene clusters in $\geq 1 \%$ of tumour cells. For calculation of the HER2/CEP17 ratio, cells with HER2 clusters were considered to have 16 HER2 signals. Chromosome 17 copy number changes were classified based on the mean number of CEP17 signals per cell according to $\mathrm{Ma}$ et al. [10]. Polysomy 17 was included in the analysis since it may interfere with calculation of the HER2/CEP17 ratio. A single pathologist blinded against the FISH results of the alternative assay and the results of the HER2 immunohistochemistry evaluated manual and automated FISH slides in a random order.

\section{Statistical analysis}

Inter-method agreement was evaluated for the following HER2 FISH parameters: HER2 copy number, CEP17 copy number, HER2/CEP17 ratio, proportion of carcinoma cells with HER2/CEP17 ratio $\geq 2.2$, HER2 amplification status, HER2 genetic heterogeneity, the presence of HER2 gene clusters, and chromosome 17 polyploidy. Correlation analyses of categorical variables were performed using contingency table analysis, chi-square test (twosided Fisher's exact test), and calculation of concordance rates and Cohen's K coefficients. Pearson's correlation coefficient and linear regression analysis were used to assess agreement of continuous variables. SPSS 16 for Windows 

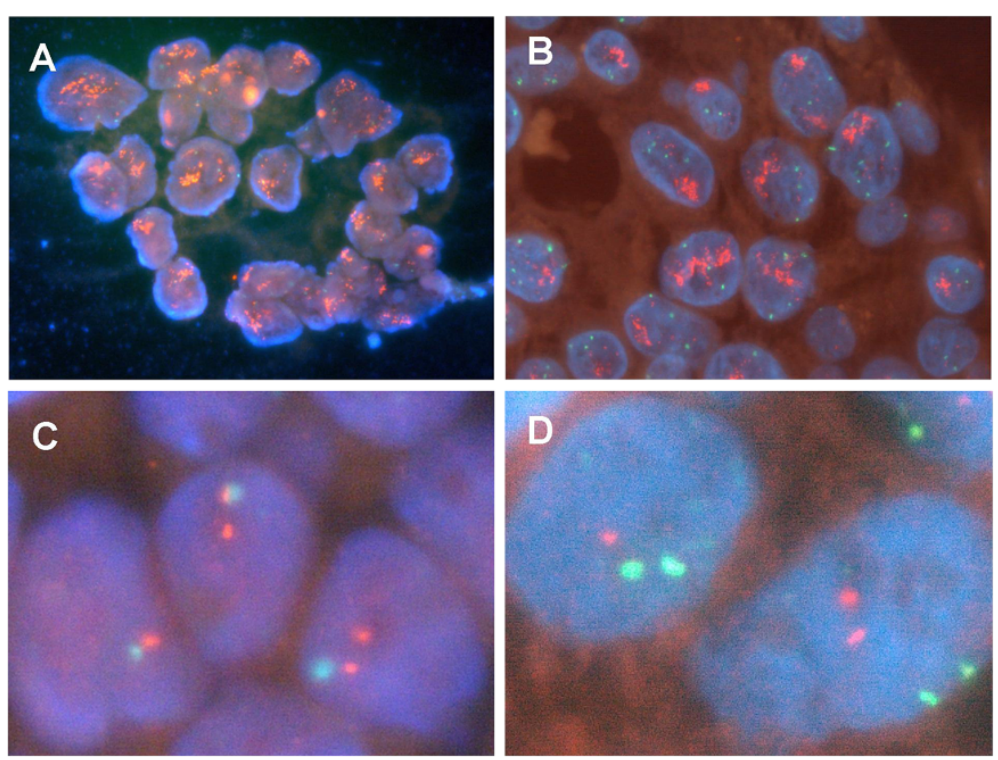

Figure 1 Manual and automated HER2/CEP17 FISH. Representative manual (A, C) and automated (B, D) HER2/CEP17 FISH results of carcinomas with (A, B) and without (C, D) HER2 gene amplification. HER2 signal red, CEP17 signal green. Original magnification $630 \times$.

(SPSS, Inc., Chicago, IL) was used. P values $<0.05$ were regarded as significant.

\section{Results}

\section{Concordance analysis for HER2 amplification status} between manual and automated HER2 FISH

Both manual and automated HER2 FISH were successfully performed on all samples (Figure 1). No HER2 FISH failures were observed. Both manual and automated FISH produced bright and distinct signals for the HER2 and CEP17 probes. Using ASCO/CAP scoring criteria for breast carcinoma, positive HER2 gene amplification status is defined by a HER2/CEP17 ratio $>2.2$ in carcinoma cells [2]. Automated and manual FISH found HER2 gene amplification in $46 \%$ and $50 \%$ of cases, respectively (Table 1 ). Four cases with HER2 gene amplification according to manual FISH tested as not amplified by automated FISH. The overall concordance rate between manual and

Table 1 Concordance analysis between manual and automated HER2 FISH for HER2 amplification status

\begin{tabular}{|c|c|c|c|c|c|c|c|c|c|c|c|c|}
\hline \multirow[t]{2}{*}{ Parameter } & \multicolumn{5}{|c|}{ Manual HER2 FISH } & \multicolumn{5}{|c|}{ Automated HER2 FISH } & \multirow[b]{2}{*}{$\begin{array}{l}\text { Concordance } \\
\text { rate }(\%)\end{array}$} & \multirow[b]{2}{*}{$\begin{array}{c}\text { Cohen's } \\
\text { kappa }\end{array}$} \\
\hline & $\begin{array}{c}0+ \\
(n=20)\end{array}$ & $\begin{array}{c}1+ \\
(n=20)\end{array}$ & $\begin{array}{c}2+ \\
(n=30)\end{array}$ & $\begin{array}{c}3+ \\
(n=30)\end{array}$ & Total & $\begin{array}{c}0+ \\
(n=20)\end{array}$ & $\begin{array}{c}1+ \\
(n=20)\end{array}$ & $\begin{array}{c}2+ \\
(n=30)\end{array}$ & $\begin{array}{c}3+ \\
(n=30)\end{array}$ & Total & & \\
\hline \multicolumn{13}{|c|}{ HER2 amplification status (HER2/CEP17 ratio >2.2) } \\
\hline Non-amplified (ratio < 1.8) & $\begin{array}{c}20 \\
(100)\end{array}$ & $15(75)$ & $9(30)$ & 0 & $\begin{array}{c}44 \\
(44)\end{array}$ & $\begin{array}{c}20 \\
(100)\end{array}$ & $19(95)$ & $10(33)$ & $1(3)$ & $\begin{array}{c}50 \\
(50)\end{array}$ & & \\
\hline Equivocal (ratio 1.8-2.2) & 0 & $5(25)$ & $1(3)$ & 0 & $6(6)$ & 0 & $1(5)$ & $2(7)$ & $1(3)$ & $4(4)$ & $96^{\#}$ & 0.920 \# \\
\hline Amplified (ratio > 2.2) & 0 & 0 & $20(67)$ & $\begin{array}{c}30 \\
(100)\end{array}$ & $\begin{array}{l}50 \\
(50)\end{array}$ & 0 & 0 & $18(60)$ & $28(93)$ & $\begin{array}{c}46 \\
(46)\end{array}$ & & \\
\hline \multicolumn{13}{|c|}{ HER2 amplification status (HER2/CEP17 ratio >2.0) } \\
\hline Non-amplified (ratio < 2.0) & $\begin{array}{c}20 \\
(100)\end{array}$ & $18(90)$ & $9(30)$ & 0 & $\begin{array}{l}47 \\
(47)\end{array}$ & $\begin{array}{c}20 \\
(100)\end{array}$ & $\begin{array}{c}20 \\
(100)\end{array}$ & $10(33)$ & $1(3)$ & $\begin{array}{l}51 \\
(51)\end{array}$ & 96 & 0.920 \\
\hline Amplified (ratio $\geq 2.0$ ) & 0 & $2(10)$ & $21(70)$ & $\begin{array}{c}30 \\
(100)\end{array}$ & $\begin{array}{l}53 \\
(53)\end{array}$ & 0 & 0 & $20(67)$ & $29(97)$ & $\begin{array}{l}49 \\
(49)\end{array}$ & & \\
\hline \multicolumn{13}{|c|}{ HER2 amplification status (Mean HER2 number $>6.0$} \\
\hline $\begin{array}{l}\text { Non-amplified (number < } \\
6.0 \text { ) }\end{array}$ & $\begin{array}{c}20 \\
(100)\end{array}$ & $\begin{array}{c}20 \\
(100)\end{array}$ & $12(40)$ & $3(10)$ & $\begin{array}{l}55 \\
(55)\end{array}$ & $\begin{array}{c}20 \\
(100)\end{array}$ & $\begin{array}{c}20 \\
(100)\end{array}$ & $14(47)$ & $4(13)$ & $\begin{array}{l}58 \\
(58)\end{array}$ & 97 & 0.939 \\
\hline Amplified (number >6.0) & 0 & 0 & $18(60)$ & $27(90)$ & $\begin{array}{l}45 \\
(45)\end{array}$ & 0 & 0 & $16(53)$ & $26(87)$ & $\begin{array}{l}42 \\
(42)\end{array}$ & & \\
\hline
\end{tabular}



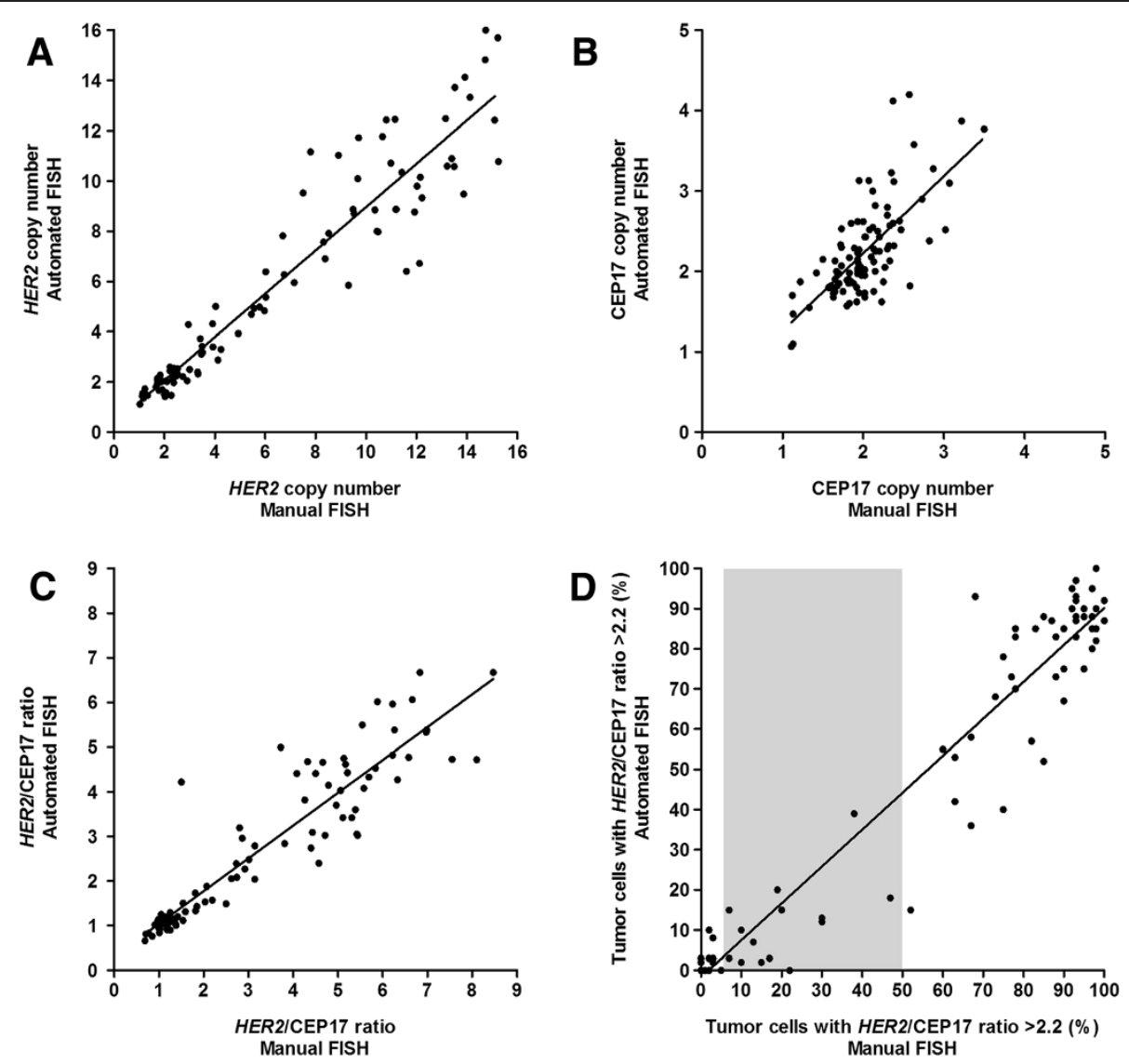

Figure 2 Manual and automated HER2 testing in breast carcinoma. Results obtained by manual and automated HER2 testing using the same area of carcinoma are shown. Each carcinoma $(n=100)$ is depicted in the graphs according to the HER2 copy number $(\mathbf{A})$, CEP17 copy number (B), HER2/CEP17 ratio (C) and proportion of carcinoma cells with HER2/CEP17 ratio >2.2 (D), respectively. Slope, intercept, and R square values of regression curves are summarized in Table 2.

automated HER2 FISH was 96\% (K coefficient 0.920). Concordance rates were $100 \%, 100 \%, 93.3 \%$ and $93.3 \%$ for carcinomas with HER2 scores $0+, 1+, 2+$ and $3+$, respectively.

In 4 cases, HER2 amplification status (HER2/CEP17 ratio $>2.2)$ was discordant between manual and automated FISH. HER2/CEP17 ratios of these cases were 2.62, 2.74, 2.5, and 3.14 for manual FISH, and 2.05, 2.08, 1.49 , and 2.04 for automated FISH, respectively. Whereas all four cases were classified as HER2 amplified based on manual FISH, 3 of these 4 cases were scored as equivocal and one case as not-amplified based on automated FISH. We therefore calculated mean HER2 signal numbers, mean CEP17 signal numbers and mean HER2/CEP17 ratios of the study cohort for both manual and automated FISH. On average, manual FISH produced more HER2 signals (Mean \pm SE: $6.41 \pm 0.46$ versus $5.87 \pm 0.42$ ), but less CEP17 signals than automated FISH (Mean \pm SE: $2.02 \pm$ 0.04 versus $2.24 \pm 0.06$ ). The mean $H E R 2 / C E P 17$ ratio for automated FISH was smaller than for automated FISH
(Mean \pm SE: $2.56 \pm 0.17$ versus $3.13 \pm 0.22$ ). These results indicate that automated HER2 FISH was associated with a trend towards lower HER2/CEP17 ratios and may underestimate the HER2 amplification status of carcinomas with HER2/CEP17 ratios close to the cut-off value 2.2.

Using 2.0 as an alternative HER2/CEP17 cut-off value, HER2 gene amplification was observed in $49 \%$ and $53 \%$ of carcinomas by automated and manual FISH, respectively (Table 1 ). The overall concordance rate between manual and automated HER2 FISH was 96\% (K coefficient 0.920 ). Concordance rates were $100 \%, 90 \%, 96.7 \%$ and $96.7 \%$ for carcinomas with HER2 immunohistochemical scores $0+, 1+, 2+$ and $3+$, respectively.

A third alternative definition of positive HER2 amplification status is based on the mean absolute HER2 gene copy number in carcinoma cells (average of $>6$ gene copies/nucleus) [2]. Using this definition, HER2 gene amplification was observed in $42 \%$ and $45 \%$ of carcinomas by automated and manual FISH, with an overall concordance rate of $96 \%$ (K coefficient 0.939 ). Concordance rates were 
Table 2 Overall concordance analysis between manual and automated HER2 for four continuous HER2/CEP17 FISH parameters

\begin{tabular}{|c|c|c|c|c|c|c|c|}
\hline \multirow[b]{2}{*}{ Parameter } & \multirow{2}{*}{$\begin{array}{c}\text { Manual HER2 } \\
\text { FISH } \\
\text { Mean } \pm \text { SD }\end{array}$} & \multirow{2}{*}{$\begin{array}{c}\text { Automated HER2 } \\
\text { FISH } \\
\text { Mean } \pm \text { SD }\end{array}$} & \multicolumn{2}{|l|}{ Correlation analysis } & \multicolumn{3}{|c|}{$\begin{array}{l}\text { Linear regression } \\
\text { analysis }\end{array}$} \\
\hline & & & Pearson correlation coefficient & $P$ value & Slope & Intercept & R square \\
\hline HER2 copy number & $6.41 \pm 4.6$ & $5.87 \pm 4.2$ & 0.947 & 0.01 & 0.863 & 0.338 & 0.898 \\
\hline CEP17 copy number & $2.02 \pm 0.43$ & $2.24 \pm 0.59$ & 0.705 & 0.01 & 0.962 & 0.299 & 0.497 \\
\hline HER2/CEP17 ratio & $3.13 \pm 2.19$ & $2.56 \pm 1.71$ & 0.943 & 0.01 & 0.738 & 0.255 & 0.890 \\
\hline $\begin{array}{l}\text { Proportion of carcinoma cells with } \\
\text { HER2/CEP17 ratio }>2.2(\%)\end{array}$ & $46.6 \pm 41.6$ & $41.1 \pm 39.4$ & 0.970 & 0.01 & 0.919 & -1.732 & 0.942 \\
\hline
\end{tabular}

100\%, 100\%, 93.3\% and 96.7\% for carcinomas with HER2 immunohistochemical scores $0+, 1+, 2+$ and $3+$, respectively.

Automated HER2 FISH was also evaluated for its ability to identify carcinomas with positive HER2 status using HER2 3+ score as reference. Concordance rates between HER2 3+ score and positive HER2 amplification status (HER2/CEP17 ratio $>2.2$ ) assessed by manual or automated HER2 FISH were $100 \%$ and $97 \%$, respectively.

\section{Concordance analysis for HER2/CEP17 FISH parameters} between manual and automated HER2 FISH

Concordance analysis was also performed for four numerical HER2/CEP17 FISH parameters (Figure 2, Table 2). Manual and automated FISH results for HER2 copy number, CEP17 copy number, HER2/CEP17 ratio and the percentage of carcinoma cells with HER2/CEP17 ratio $>2.2$ showed high correlation (Pearson correlation coefficient $0.947,0.705,0.943$, and 0.970 , respectively). Linear regression analysis revealed that HER2 copy numbers, CEP17 copy numbers, HER2/CEP17 ratios and the percentages of carcinoma cells with HER2/CEP17 ratio $>2.2$ obtained by automated HER2 FISH were highly consistent with the results of the manual assay (Table 2). Using Student's $t$ test for comparison, no significant differences between results of manual and automated FISH were observed for any of the four numerical HER2/CEP17 FISH parameters analysed.

HER2 genetic heterogeneity, HER2 clusters and CEP17 polysomy were identified in $17 \%, 41 \%$ and $4 \%$ of cases by manual FISH and in 14\%, 39\% and $12 \%$ of cases by automated FISH, respectively. Concordance rates between automated and manual HER2 FISH results were high for all categorical HER2/CEP17 FISH parameters (Table 3).

Detailed comparison of manual and automated FISH results was also performed for carcinoma subgroups according to HER2 immunohistochemical score. Results for HER2 copy number, CEP17 copy number, HER2/ CEP17 ratio and the percentage of carcinoma cells with HER2/CEP17 ratio >2.2 were comparable between manual and automated FISH irrespective of HER2 immunohistochemical score (data not shown). No significant difference was observed for any of continuous HER2/ CEP17 FISH parameters using Student's $t$ test. Within carcinoma subgroups according to HER2 immunohistochemical score, HER2 genetic heterogeneity, HER2 clusters and CEP17 polyploidy were detected with comparable relative frequencies using manual and automated HER2 FISH (data not shown).

Table 3 Overall concordance analysis between manual and automated HER2 for three categorical HER2/CEP17 FISH parameters

\begin{tabular}{|c|c|c|c|c|c|c|}
\hline & $\begin{array}{l}\text { Manual HER2 } \\
\text { FISH (\%) }\end{array}$ & $\begin{array}{c}\text { Automated HER2 } \\
\text { FISH (\%) }\end{array}$ & $\begin{array}{c}\text { Pearson chi }{ }^{2} \\
\text { coefficient }\end{array}$ & $P$ value & $\begin{array}{l}\text { Concordance } \\
\text { rate (\%) }\end{array}$ & $\begin{array}{c}\text { Cohen's } \\
\text { kappa }\end{array}$ \\
\hline \multicolumn{7}{|l|}{ HER2 genetic heterogeneity } \\
\hline Present (5-50\% carcinoma cells with HER2/CEP17 ratio >2.2) & 17 & 14 & 18.59 & $<0.001$ & 85 & 0.428 \\
\hline Absent & 83 & 86 & & & & \\
\hline \multicolumn{7}{|l|}{ HER2 cluster } \\
\hline Present (HER2 cluster in >1\% cells) & 41 & 39 & 76.71 & $<0.001$ & 94 & 0.875 \\
\hline Absent & 59 & 61 & & & & \\
\hline \multicolumn{7}{|l|}{ CEP17 polyploidy } \\
\hline Present (Chr. 17 copy number $>3.00$ ) & 4 & 12 & 15.66 & $<0.001$ & 90 & 0.335 \\
\hline Absent & 96 & 88 & & & & \\
\hline
\end{tabular}




\section{Discussion}

We compared automated with manual FISH using the same HER2 and CEP17 probes in a large series of breast carcinoma core biopsies. Inter-method agreement was excellent for HER2 amplification status using three different definitions (HER2/CEP17 ratio > 2.2, HER2/CEP17 ratio $>2.0$, mean $H E R 2$ number $>6.0$ ) with overall concordance rates of $96 \%, 96 \%$ and $97 \%$, respectively. Agreement was excellent over the complete range of HER2 immunohistochemical scores. We also observed high inter-method correlation for other categorical (HER2 genetic heterogeneity, presence of HER2 gene clusters and CEP17 polyploidy) and numerical variables (HER2 copy number, CEP17 number and HER2/CEP17 ratio) between automated and manual FISH. Our results indicate that automated HER2 FISH is a reliable method to determine the HER2 gene amplification status in breast carcinomas and fulfills ASCO/CAP requirements for test validation of $>95 \%$ concordance for amplified versus nonamplified cases [2].

Inter-method concordance analysis of biomarker assessment in FFPE breast carcinoma tissues can be negatively affected by various pre-analytical, analytical and post-analytical variables $[2,11]$. To limit variability we used core biopsies as material for our method comparison. Core biopsies are more homogeneous than resection specimens and tissue-microarray cores with regard to fixation conditions and more closely resemble the clinical situation in which HER2 FISH is often performed on core biopsies, especially in patients in whom neo-adjuvant chemotherapy is considered. The HER2 status of invasive carcinoma cells was analysed by selecting areas of invasive carcinoma on haematoxylin-eosin stained sections. The reliability/ concordance of the manual and automated FISH tests was assessed by comparing the results of automated and manual FISH obtained from the same carcinoma area. Scoring was performed by a single person experienced in FISH testing to reduce inter-observer variability. This approach closely resembles the process of HER2 status determination in routine diagnostics. Therefore, our results show that automated HER2 FISH is a feasible and effective method for HER2 status determination in clinical practice.

In diagnostic pathology, the degree of automation is advanced for conventional and immunochemical staining methods. The potential advantages of total automation are decreased personnel and operating costs, less human intervention and fewer laboratory errors, more rapid processing of samples and recording of results, increased safety, better control of the entire process, and decreased need for laboratory space. In our study, we evaluated for the first time a fully automated HER2 FISH assay. Similar to FISH, HER2 assays using silver-enhanced in-situ hybridization (SISH) or chromogenic in-situ hybridization $(\mathrm{CISH})$ allow for simultaneous visualization of HER2 and CEP17 signals within the same carcinoma cell nucleus [3]. Various HER2 bright field in-situ hybridization assays are available (e.g. Dako HER2 CISH pharmDX ${ }^{\text {tm }}$ Kit, Ventana INFORM HER2 Dual ISH Assay, Zytovision ZytoDot 2C). Using manual HER2 FISH as a reference and both histological and cytological material of various cancer types, automated bright field HER2 assays have demonstrated comparable results suggesting that they represent reliable methods for HER2 status determination [6,7,12-14]. Our results indicate that the same holds true for automated HER2 FISH. Future studies may directly compare automated HER2 FISH with automated single-colour or dual-colour CISH assays.

\section{Conclusion}

In conclusion, our study indicates that automated HER2/CEP17 FISH is a reliable in situ method to analyse the HER2 amplification status and in the future may represent a clinically useful tool for standardised and objective HER2 status evaluation of carcinoma cells, especially in combination with automated image analysis tools.

\section{Competing interests}

Supported by Leica.

\section{Authors' contributions}

The study was planned by CO, DK, MH and WJ. Data acquisition was conducted by DK and CO. Data analysis was performed by WJ. WJ wrote the manuscript with help from $C O$. All authors read and approved the final manuscript.

Received: 8 June 2012 Accepted: 11 April 2013 Published: 20 April 2013

\section{References}

1. Goldhirsch A, Wood WC, Coates AS, Gelber RD, Thurlimann B, Senn HJ: Strategies for subtypes--dealing with the diversity of breast cancer: highlights of the St. Gallen international expert consensus on the primary therapy of early breast cancer 2011. Ann Oncol 2011, 22(8):1736-1747.

2. Wolff AC, Hammond ME, Schwartz JN, Hagerty KL, Allred DC, Cote RJ, Dowsett M, Fitzgibbons PL, Hanna WM, Langer A, et al: American society of clinical oncology/college of American pathologists guideline recommendations for human epidermal growth factor receptor 2 testing in breast cancer. J Clin Oncol 2007, 25(1):118-145.

3. Gruver AM, Peerwani Z, Tubbs RR: Out of the darkness and into the light: bright field in situ hybridisation for delineation of ERBB2 (HER2) status in breast carcinoma. J Clin Pathol 2010, 63(3):210-219.

4. Mayr D, Heim S, Weyrauch K, Zeindl-Eberhart E, Kunz A, Engel J, Kirchner T: Chromogenic in situ hybridization for Her-2/neu-oncogene in breast cancer: comparison of a new dual-colour chromogenic in situ hybridization with immunohistochemistry and fluorescence in situ hybridization. Histopathology 2009, 55(6):716-723.

5. Shousha S, Peston D, Amo-Takyi B, Morgan M, Jasani B: Evaluation of automated silver-enhanced in situ hybridization (SISH) for detection of HER2 gene amplification in breast carcinoma excision and core biopsy specimens. Histopathology 2009, 54(2):248-253.

6. Fritzsche FR, Bode PK, Moch $\mathrm{H}$, Kristiansen G, Varga Z, Bode B: Determination of the Her-2/neu gene amplification status in cytologic breast cancer specimens using automated silver-enhanced in-situ hybridization (SISH). Am J Surg Pathol 2010, 34(8):1180-1185.

7. Garcia-Caballero T, Grabau D, Green AR, Gregory J, Schad A, Kohlwes E, Ellis IO, Watts S, Mollerup J: Determination of HER2 amplification in primary 
breast cancer using dual-colour chromogenic in situ hybridization is comparable to fluorescence in situ hybridization: a European multicentre study involving 168 specimens. Histopathology 2010, 56(4):472-480.

8. Koh YW, Lee HJ, Lee JW, Kang J, Gong G: Dual-color silver-enhanced in situ hybridization for assessing HER2 gene amplification in breast cancer. Mod Pathol 2011, 24(6):794-800.

9. Vance GH, Barry TS, Bloom KJ, Fitzgibbons PL, Hicks DG, Jenkins RB, Persons DL, Tubbs RR, Hammond ME: Genetic heterogeneity in HER2 testing in breast cancer: panel summary and guidelines. Arch Pathol Lab Med 2009, 133(4):611-612.

10. Ma Y, Lespagnard L, Durbecq V, Paesmans M, Desmedt C, Gomez-Galdon M, Veys I, Cardoso F, Sotiriou C, Di Leo A, et al: Polysomy 17 in HER-2/neu status elaboration in breast cancer: effect on daily practice. Clin Cancer Res 2005, 11(12):4393-4399.

11. Hammond ME, Hayes DF, Dowsett M, Allred DC, Hagerty KL, Badve S, Fitzgibbons PL, Francis G, Goldstein NS, Hayes M, et al: American society of clinical oncology/college of American pathologists guideline recommendations for immunohistochemical testing of estrogen and progesterone receptors in breast cancer. J Clin Oncol 2010, 28(16):2784-2795.

12. Bartlett JM, Campbell FM, Ibrahim M, O'Grady A, Kay E, Faulkes C, Collins N, Starczynski J, Morgan JM, Jasani B, et al: A UK NEQAS ISH multicenter ring study using the Ventana HER2 dual-color ISH assay. Am J Clin Pathol 2011, 135(1):157-162.

13. Brugmann A, Lelkaitis $G$, Nielsen $S$, Jensen $K G$, Jensen V: Testing HER2 in breast cancer: a comparative study on BRISH, FISH, and IHC. Appl Immunohistochem Mol Morphol 2011, 19(3):203-211.

14. Yan B, Choo SN, Mulyadi P, Srivastava S, Ong CW, Yong KJ, Putti T, SaltoTellez M, Lim GS: Dual-colour HER2/chromosome 17 chromogenic in situ hybridisation enables accurate assessment of HER2 genomic status in ovarian tumours. J Clin Pathol 2011, 64(12):1097-1101.

doi:10.1186/1472-6890-13-13

Cite this article as: Öhlschlegel et al:: Comparison of automated and manual FISH for evaluation of HER2 gene status on breast carcinoma core biopsies. BMC Clinical Pathology 2013 13:13.

\section{Submit your next manuscript to BioMed Central and take full advantage of:}

- Convenient online submission

- Thorough peer review

- No space constraints or color figure charges

- Immediate publication on acceptance

- Inclusion in PubMed, CAS, Scopus and Google Scholar

- Research which is freely available for redistribution 